\title{
Decisões de Investimentos de Empresas Familiares Brasileiras
}

\section{Investment Decisions of Brazilian Family Firms}

\author{
Thiago Henrique Moreira Goes \\ Universidade Federal do Paraná - UFPR - Brasil \\ thiagogoes@ufpr.br \\ ORCID: 0000-0002-6088-4093 \\ Cláudio Antônio Pinheiro Machado Filho \\ Universidade de São Paulo - USP - Brasil \\ capfilho@usp.br \\ ORCID: 0000-0002-6733-5142
}

Submetido em 03/07/2020; Aprovado em 02/08/2020.

\begin{abstract}
Resumo
Objetivo: Entre os principais determinantes de uma política de investimentos estão a estrutura de propriedade e o comportamento dos gestores. Nesta vertente, um segmento de empresas com características específicas que se sobressaem nas políticas de investimento são as empresas familiares. Assim, o objetivo da pesquisa consistiu em analisar o impacto da estrutura de propriedade familiar nas decisões de investimento das empresas brasileiras entre os períodos de crises econômicas (2009-2013), considerados satisfatórios para a economia e caracterizados pela normalidade institucional. Metodologia: 0 estudo apresenta um modelo de regressões lineares múltiplas elaboradas para testar o impacto de várias variáveis sobre uma variável dependente em uma relação simultânea. A variável dependente consistiu no índice de investimento em CapEx realizado pelas empresas. A variável de interesse foi uma variável dummy se a empresa era familiar ou não. Além disso, foram realizados testes para identificar os momentos da companhia, ou seja, testar o comportamento das empresas quando estas estavam melhores ou piores do que suas concorrentes não familiares. Resultados: Os resultados corroboram os pressupostos de autopreservação, visto que as empresas familiares investiram 13,5\% menos do que as não familiares. Contudo, as empresas familiares, quando apresentam resultados piores que suas concorrentes, investem até $24 \%$ mais do que as não familiares. Desta forma, a pesquisa sustenta as hipóteses de que as empresas familiares estão mais alinhadas ao comportamento de autopreservação nas decisões de investimento. Contribuições teóricas: A pesquisa proporciona uma análise sobre os chamados mixed-gambles das empresas familiares, ou seja, a aversão ao risco e a busca pela perpetuidade da companhia, demonstrados pelo uso da variável dummy e pelos testes complementares com situações econômicas favoráveis e desfavoráveis. Contribuições práticas: Foram encontrados resultados que apontam o comportamento de maior autopreservação das empresas brasileiras em relação aos seus investimentos.
\end{abstract}

Palavras-chave: investimento, bens de capital, empresas familiares, riqueza socioemocional, autopreservação.

\begin{abstract}
Objective: Among the main determinants of an investment policy are a property structure and the behavior of managers. In this regard, a segment of companies that have specific characteristics that stand out in investment policies are like family businesses. Thus, the objective of the research was to analyze the impact of the structure of family ownership on investment decisions of Brazilian companies between periods of protection crisis (2009-2013), as these periods were considered satisfactory for the economy and for institutional normality. Methodology: The study presents a model of multiple linear regressions designed to test the impact of several variables on a dependent variable in a simultaneous relationship. The dependent variable consisted of the CapEx investment index made by the companies. The variable of interest was a dummy variable whether the company was familiar or not. In addition, tests were carried out to identify the company's moments, that is, to test the behavior of companies when they were
\end{abstract}


better or worse than their unfamiliar competitors. Results: The results corroborate the assumptions of self-preservation, since family companies invested $13.5 \%$ less than non-family companies. However, family businesses when they perform worse than their competitors invest up to $24 \%$ more than nonfamily businesses. Thus, the research supports the hypothesis that family businesses are more aligned with the self-preservation behavior in investment decisions. Theoretical contributions: The research provides an analysis of the so-called mixed-gambles of family businesses, that is, risk aversion and the search for the company's perpetuity, which is demonstrated by the dummy variable and the complementary tests with favorable and unfavorable economic situations. Practical contributions: Results were found that point to the behavior of greater self-preservation of Brazilian companies in relation to their investments.

Keywords: investment, capital goods, family businesses, socioemotional wealth, self-preservation.

\section{Introdução}

Políticas de investimento estão entre os mais importantes itens das finanças corporativas. Devido a essa importância, muitas pesquisas sobre o tema focaram nos investimentos como geradores de valor (Myers \& Majluf, 1984) e nas características que podem ser consideradas determinantes do nível de investimentos. Algumas podem ser de macroeconomia e de instituição (Baysinger, Kosnik \& Turk, 1991; Campello, Graham \& Harvey, 2010), de liquidez (Cleary, 1999; Cleary, 2000), de estrutura de propriedade (Anderson, Duru \& Reeb., 2012), de tamanho e tangibilidade das organizações (Almeida \& Campello, 2007) e de visão dos gestores e investidores (Malmendier \& Tate, 2005; Gervais \& Odean, 2001; Graham, Harvey \& Puri, 2013).

A partir deste cenário de influência sobre as políticas de investimento, muitas pesquisas foram construídas ao longo do tempo a partir de modelos econométricos que consideravam as características da firma como determinantes do nível de investimento. Entretanto, as pesquisas sobre os impactos das características das empresas familiares são relativamente recentes (Chrisman \& Patel, 2012). Os trabalhos buscam analisar a estrutura de propriedade familiar, que é baseada, especialmente, nos desejos de perpetuidade e de manutenção do controle (Anderson et al., 2012; Chua, Chrisman e De Massis, 2015).

Portanto, o problema de pesquisa consistiu em analisar o impacto da propriedade e do controle familiar nas decisões de investimentos em períodos de normalidade institucional, ou seja, sem crises econômicas ou políticas, pois o interesse consiste em averiguar se as teorias financeiras para empresas familiares se adequam ao contexto brasileiro. Deve-se dizer que, embora a crise de 2008 tenha afetado de forma grave países como os Estados Unidos e outros países da União Europeia, o Brasil foi menos afetado e se pautou por um modelo econômico expansionista que proporcionou grandes fontes de investimento (sobretudo com apoio de bancos e fundos públicos) (Gonçalves, 2015; Gonçalves \& Guimarães, 2015). Além disso, a pesquisa buscou analisar o impacto da interação entre propriedade e controle familiar em outras variáveis específicas da firma. A importância de pesquisas como o presente trabalho refere-se ao uso de modelos econométricos tradicionais aplicados ao Brasil e à aplicação destes modelos em um período de normalidade. Ademais, conforme evidenciado por Borges, Lescura e Oliveira (2012), não existem muitas pesquisas sobre empresas familiares e investimento e endividamento.

A metodologia utilizou dados de empresas brasileiras listadas em bolsa, excluindo as do setor financeiro e de utilidade pública. Dessa maneira, o total de empresas da amostra foi 238, observadas entre os anos de 2009 e 2013, para os formulários de referência consolidados ao final do período. A amostra total consistiu em um número final de observações de 1.190 empresas. Os métodos empregados consistiram em três equações diferentes testadas por OLS e Dados em Painel com Efeitos Aleatórios seguindo o método quantitativo de Anderson et al. (2012). Além desses modelos, a amostra foi separada em duas para a realização dos testes de robustez para a comprovação de pressupostos teóricos, concernentes ao impacto da riqueza socioemocional e da visão de longo prazo nas decisões de investimento, apresentados por Chrisman e Patel (2012). A variável dependente escolhida como foco de análise foi o investimento em bens de capital (CapEx).

Os resultados, em linha com as hipóteses, apresentaram que as empresas familiares realizaram investimentos até $13,5 \%$ menores do que as não familiares durante o período analisado. Como elementos de robustez, os últimos testes contemplaram uma separação amostral entre empresas com receitas abaixo e acima da mediana. As empresas familiares com receitas abaixo da mediana apresentaram dispêndios de capital $24 \%$ maiores do que as não familiares. Contrariamente, as empresas familiares com receitas acima da mediana apresentaram dispêndios de capital 12\% menores do que as não familiares. 
Esses resultados atenderam as hipóteses delineadas pela pesquisa e complementam os pressupostos da riqueza socioemocional e da autopreservação de empresas familiares (Miller, Le Breton-Miller \& Lester, 2011; Chrisman \& Patel, 2012; Chua et al., 2015).

Afora esta introdução, a segunda parte deste artigo discorre sobre as diretrizes da política de investimento das firmas, as características de investimento das empresas familiares e as hipóteses da pesquisa. A terceira parte descreve os dados, a metodologia e a amostra da pesquisa. Em seguida, a quarta parte apresenta e discute os resultados descritivos e dos modelos estatísticos. Por fim, a quinta parte expõe as considerações finais.

\section{Política de investimentos das empresas familiares}

\subsection{Política de investimentos das firmas}

As decisões de investimento podem variar segundo a restrição ao crédito da empresa. Para isso, torna-se importante a discussão de duas importantes variáveis: fluxo de caixa livre e tangibilidade da empresa (Cleary, 1999; Almeida \& Campello, 2007; Agca \& Mozumdar, 2008). Além dessas duas variáveis, o contexto macroeconômico, o ambiente institucional, a estrutura de propriedade das empresas e o comportamento dos tomadores de decisão devem ser considerados (Baysinger et al., 1991; Campello et al., 2010; Graham et al., 2013).

Embora o chamado "status financeiro" das empresas não fosse contemplado por Modigliani e Miller (1958) devido à consideração da existência de um mercado perfeito de capitais, as características da firma e a sua relação com a sensibilidade nos investimentos passaram a ser fortemente analisadas ao longo do tempo (Cleary, 1999). Myers e Majluf (1984), Fazzari, Hubbard e Petersen (1988) e Kaplan e Zingales (1997) constataram a existência de um modelo hierárquico na estrutura de capital das empresas, que resulta em impactos diretos nas decisões de investimento. Para Cleary (1999) e Cleary (2000), a realização de investimentos pelas empresas é altamente dependente de sua liquidez, mormente para as empresas que necessitam de recursos externos para a realização de investimentos. Diante disso, o fluxo de caixa e a tangibilidade são elementos com grande peso para a realização de investimentos (Brown \& Petersen, 2009). 0 fluxo de caixa possui uma relação de U com as decisões de investimento, pois as empresas com baixo fluxo de caixa realizam investimentos elevados para se recuperarem (Kaplan \& Zingales, 1997; Cleary, 1999; Cleary, Povel \& Raith, 2007). Já a tangibilidade funciona como um elemento de salvaguarda para os credores, o que tende a diminuir a restrição ao crédito das empresas (Almeida \& Campello, 2007; Guariglia, 2008).

Pode-se dizer que o comportamento do tomador de decisão e a estrutura de propriedade são itens complementares. Quanto à estrutura de propriedade, muitos trabalhos consideraram como problemática a existência de uma estrutura de propriedade dispersa, pois possibilitaria a realização de investimentos em condições de baixas oportunidades de crescimento, o que afetaria negativamente o fluxo de caixa livre destinado aos acionistas, ou seja, geraria um conflito de agência entre acionistas e gestores (Jensen \& Meckling, 1976; Fama \& Jensen, 1983). Os dois conflitos de agência comumente analisados são os do Tipo 1 e do Tipo 2 . 0 conflito de agência do tipo I é aquele que ocorre em função das divergências de interesse entre os gestores e os acionistas em uma estrutura dispersa. Já o conflito de agência do tipo II é aquele em que um blockholder pode fazer uso de seu poder para prejudicar os acionistas minoritários (Shleifer \& Vishny, 1997; Villalonga \& Amitt, 2006).

No que concerne aos investimentos em CapEx (ex.: máquinas e equipamentos), objeto desta pesquisa, pode-se dizer que eles demandam grandes recursos das empresas e são considerados densos e não recorrentes (Dudley, 2012). Além disso, os bens de capital são considerados elementos fundamentais para a geração de inovações e para os ganhos de produtividade. Massell (1962) afirma que o crescimento histórico dos Estados Unidos tem grande relação com as aquisições de novas tecnologias, máquinas e equipamentos. Alves, Gomes e Cavalcante (2014) apresentaram pesquisa similar para o Brasil e afirmaram que o foco das pesquisas recentes em Pesquisa e Desenvolvimento (P\&D) tem mascarado a importância da aquisição de capital imobilizado (bens de capital) para a inovação tecnológica das empresas, sobretudo aquelas de países em desenvolvimento que ainda estão defasadas em termos técnicos. Os resultados relatados por esses autores mostram que incorporações de $1 \%$ em novas tecnologias de processo representam um aumento de $0,15 \%$ de produtividade para as empresas brasileiras. Por fim, a Pesquisa de Inovação do Instituto Brasileiro de Geografia e Estatística (IBGE) (2020) elucida que, dos valores gastos com atividades inovativas em 2017, 31,5\% foram destinados aos investimentos em 
máquinas e equipamentos.

\subsection{Política de investimentos das empresas familiares}

Várias hipóteses teóricas afirmam que as empresas familiares são consideradas mais avessas ao risco, o que, em tese, fomentaria um menor grau de inovações. Não obstante, caso a família tivesse grande interesse em inovar, isso seria feito de forma mais rápida pela menor burocracia e pelo maior poder de decisão da família nessas empresas (Schulze, Lubatkin \& Dino, 2003). Empresas familiares realizam investimentos considerados mais seguros ao longo do tempo e mais tendentes à manutenção da empresa sob o controle da família e evitam investimentos que ponham em perigo seu capital familiar (Miller et al., 2011; Patel \& Cooper, 2014).

Empresas familiares comumente possuem o interesse de continuidade do controle da família (Anderson \& Reeb, 2003; Zellweger, 2007; Miller et al., 2011). Ante esse objetivo de manutenção do controle sobre as decisões e da não existência do conflito de agência I, as empresas familiares poderão realizar investimentos com maior eficiência (NPV positivo) e mitigar o comportamento míope dos gestores (no que se refere aos grandes investimentos) mesmo possuindo um comportamento de investimentos mais conservador do que as não familiares (James, 1999; Anderson \& Reeb, 2003).

Outro item importante consiste no impacto da riqueza socioemocional (SEW) nas decisões financeiras. A riqueza socioemocional (SEW) consiste em um elemento derivado do modelo comportamental da teoria da agência (Wiseman \& Gomez-Mejia, 1998; Berrone, Cruz \& Gomez-Mejia, 2012). Este modelo pressupõe a existência da percepção de risco por parte dos gestores e prevê, portanto, que quando sujeitos a um bom sistema de governança corporativa, isto é, a premiações por desempenho e a baixo risco de danos em seu capital reputacional, os gestores realizarão investimentos mais cuidadosos com os fluxos de caixa livres de uma empresa (Shleifer \& Vishny, 1997; Wiseman \& Gomes-Mejia, 1998).

Como elementos complementares à aversão ao risco e aos impactos da riqueza socioemocional nas decisões de investimento estão os aspectos macroeconômicos, tais como as crises financeiras. No tocante aos impactos macroeconômicos, as empresas familiares agem de forma mais conservadora. Resgatando as afirmações de Campello et al. (2010) para um momento de crise econômica e seus impactos na restrição de crédito, pode-se afirmar que as empresas naturalmente diminuem o volume de seus investimentos tendo em vista um momento de contração, já que os gestores assimilam esse momento como arriscado para realizar investimentos vultuosos. Seguindo este modelo, as empresas familiares apresentam uma vocação mais conservadora focada na manutenção da estabilidade da empresa e voltada para a perpetuidade (Gallo, Tàpies \& Cappuyns, 2004; Blanco-Mazagatos, Quevedo-Puente \& Castrillo, 2007). Outros pontos importantes consistem nas restrições de liquidez causadas por mercados de capitais e de crédito pouco desenvolvidos (Almeida e Campello, 2007), como as pesquisas analisando a estrutura de capital das empresas brasileiras evidenciam (Kayo, Brunaldi \& Aldrighi, 2018). Quando confrontadas com essa situação, o nível de investimento é menor pelas dificuldades em captar crédito. 0 custo elevado de endividar-se pode aumentar o risco de dificuldades financeiras, de estresse financeiro e, no limite, de falência. Desta forma, as empresas familiares analisam esse risco como elevado se o custo de capital for alto (Crespí \& Martín-Oliver, 2015; Gallo et al., 2004)

A partir das descrições prévias é possível detalhar as políticas de investimento das empresas familiares. Anderson et al. (2012) apontaram que as empresas caracterizadas por posse ou controle familiar realizam investimentos de longo prazo menores do que as não familiares (com um percentual 7,5\% menor). Porém, ao separar os tipos de investimento em dois, os resultados foram os seguintes:

a) Dispêndios de capital com investimentos físicos, tais como bens e máquinas (CAPEX), apresentam um resultado $15,55 \%$ superior para as empresas familiares;

b) Investimentos em P\&D, por outro lado, apresentam valores de aproximadamente $31 \%$ menores para as empresas familiares.

Segundo Kothari, Laguerre \& Leone (2002), os investimentos impelidos em bens de capital (capital expenditures - CapEx) são considerados de menor risco do que os investimentos em P\&D. Empresas familiares comumente agem de maneira mais conservadora e tomam atitudes relutantes em relação a um modelo especulativo de crescimento de longo prazo, portanto, grandes investimentos em P\&D se enquadram neste contexto (Miller et al., 2011). Para Gomez-Mejia, Campbell, Martin, Hoskisson, Makri e Sirmon (2013), os investimentos em bens de capital tendem a ser maiores porque os investimentos em P\&D podem necessitar de uma perda de controle da organização para a adoção dessas novas 
tecnologias, pois terão de ser importados novos conhecimentos, novos agentes e novos parceiros para dentro da organização. Dessa maneira, a incorporação de novos itens pode gerar uma perda na riqueza socioemocional.

Contudo, mesmo frente ao objetivo de preservar a riqueza socioemocional e realizando menos investimentos arriscados do que empresas não familiares, tais organizações, quando são comandadas por seus fundadores, podem também ter comportamentos mais ousados de investimentos. Outra situação favorável à realização de investimentos mais arriscados pode ocorrer quando os grupos familiares visam a longevidade da companhia nas mãos da família (Gomez-Mejia et al., 2013; Miller, Le BretonMiller \& Lester, 2010; Patel \& Cooper, 2014).

Chrisman e Patel (2012) corroboraram essa afirmação ao apresentarem em quais contextos a riqueza socioemocional faria com que as empresas familiares investissem mais ou menos do que as não familiares. As empresas familiares apresentam um comportamento não linear de investimentos, diferentemente das não familiares (Blanco-Mazagatos et al., 2007; Gomez-Mejia et al., 2013). Enquanto as empresas não familiares possuem um comportamento de investimento com quedas graduais ao longo do tempo (apenas com investimentos incrementais), as familiares, baseadas na riqueza socioemocional, investem volumes maiores quando estão longe da média dos resultados e quando estão acima da média das demais empresas (Anderson et al., 2012; Chrisman \& Patel, 2012).

Pode-se afirmar que as empresas familiares geralmente agem visando uma maior autopreservação do que as não familiares (Miller, Le Breton-Miller \& Lester, 2011). Diante disso, seus investimentos podem ter contornos menos arriscados - são menores do que os das empresas não familiares. Já para investimentos em bens de capital, o dispêndio de recursos é maior do que o das empresas não familiares (Anderson et al., 2012). Além disso, como os gastos das empresas familiares podem ser considerados não lineares, elas sofrem mais sensivelmente os impactos macroeconômicos e dos marcos regulatórios (Ellul, Pagano \& Panuzi et al., 2010).

\subsection{Hipóteses da pesquisa}

A primeira hipótese da pesquisa consiste no impacto das características de controle e propriedade familiar nas decisões de investimento.

$H_{1}$ - 0 nível de investimento das empresas familiares é menor do que o das não familiares.

Entende-se que as empresas familiares são mais propensas a realizar investimentos maiores em CapEx do que as não familiares (Blanco-Mazagatos et al., 2010; Anderson et al., 2012). Todavia, o país possui alguns condicionantes que impactam nessas características, tais como os problemas de liquidez e a dificuldade de concessão de crédito, sobretudo para empresas menores (Brunaldi, Kayo \& Securato, 2015). Logo, como empresas familiares possuem menor tamanho, estas tendem a ter menor capacidade para endividamento e investimento. Neste sentido, em um ambiente de crédito limitado e com altos riscos envolvendo o endividamento, as empresas familiares possivelmente vão agir visando minimizar o risco de seus investimentos, consequentemente aportando menos recursos para estes fins (Miller et al., 2011).

A segunda hipótese versa sobre o impacto da combinação entre a propriedade familiar e as características estruturais da empresa (oportunidade de crescimento, tamanho, fluxo de caixa e tangibilidade)

$H_{2}$ - A interação entre a variável familiar e as variáveis estruturais possuem impacto negativo para as políticas de investimento.

Segundo Chrisman e Patel (2012) e Patel e Cooper (2014), as empresas familiares possuem investimentos não lineares, os quais tendem a ter quedas acentuadas conforme elas chegam próximas aos seus objetivos econômicos. As empresas mantêm, portanto, o objetivo de autopreservação e não arriscam novos investimentos, mesmo em período de normalidade institucional.

A terceira hipótese a ser testada consiste na interação da estrutura de propriedade com a idade da firma (proxy para perpetuidade) e seus impactos nas decisões de investimento.

$H_{3}$ - A interação entre a variável relativa à propriedade familiar e a idade da empresa (como proxy para perpetuidade) terá impacto positivo nas decisões de investimento.

A partir das particularidades das empresas familiares mencionadas anteriormente, como o foco 
no longo prazo e a tomada de decisões voltadas à manutenção da propriedade sob o controle da família (Miller et al., 2007), espera-se que as empresas familiares, conforme avançam em termos de período de existência, possam aumentar seus investimentos visando melhores resultados para a empresa (ganhos econômicos) e para a família (ganhos não econômicos).

$H_{4}$ - Ao separar as amostras em empresas com receitas abaixo e acima de um dado ponto-alvo (mediana das empresas da amostra), as variáveis empresa familiar e interação entre propriedade familiar e idade terão impactos positivos na amostra com receitas abaixo da mediana.

Tomando como base os aspectos latentes do conceito de riqueza socioemocional, como a valorização do patrimônio da família e a busca pela maximização da riqueza para os seus membros (Sharma \& Salvato, 2011; Chrisman \& Patel, 2012; Miller et al., 2010; Patel \& Cooper, 2013), espera-se que, em um momento de problemas financeiros enfrentados pela empresa, ela busque agir com menos conservadorismo em decisões financeiras, visando os ganhos futuros.

$H_{5}$ - A combinação entre a variável familiar e as variáveis estruturais possui impacto negativo para as políticas de investimento mesmo separando as amostras em dois segmentos.

Apesar de empresas mais tangíveis ou dotadas de grande robustez em termos de tamanho sofrerem menos problemas relacionados a uma possível restrição de crédito (Almeida \& Campello, 2007; Campello et al., 2010), os investimentos em bens de capital não serão realizados a todo momento. Unindo essa característica ao conceito de riqueza socioemocional, pode-se dizer que as empresas não realizarão investimentos quando considerarem que seu tamanho é satisfatório (Chua et al., 2015).

\section{Dados e Metodologia}

\subsection{Caracterização da variável empresa familiar e da variável investimento}

Uma visão importante para mensurar uma variável familiar foi elaborada por La Porta, Lopez-deSilanez e Shleifer (1999), que estabeleceram a existência de, ao menos, 20\% de controle acionário por uma família. Outras classificações mais robustas (principalmente para utilização em modelos econométricos) se encontram nos trabalhos de Anderson e Reeb (2003), Chrisman e Patel (2012) e Gedajlovic, Carney, Chrisman e Kellermanns (2012), os quais utilizaram como critério não somente a propriedade por parte de uma família, mas também a posição de um ou mais membros da família exercendo funçõeschave na organização (presença no Conselho de Administração ou nos cargos de direção).

Sendo assim, a pesquisa estabeleceu como empresas familiares aquelas em que a família possuísse, ao menos, $20 \%$ da propriedade, somando-se à presença de membros nos cargos de direção e/ou na presidência ou vice-presidência do conselho.

A outra variável importante do trabalho consiste na variável de interesse (dependente), qual seja, o investimento em bens de capital (CapEx). Para normalização dessa variável foi criado um índice de investimento em bens de capital em relação ao tamanho da empresa (ativos totais), conforme fórmula a seguir.

$$
\text { Índice de investimentos }=\text { CapEx/Ativos Totais }
$$

\subsection{Amostra}

A amostra selecionada para a pesquisa consistiu nas empresas brasileiras listadas na B3 - a Bolsa do Brasil nos anos de 2009 a 2013, totalizando 238 empresas brasileiras de capital aberto. Optou-se por excluir apenas as empresas financeiras e ligadas à utilidade pública, ou seja, os demais segmentos foram totalmente contemplados independentemente de a empresa ter fechado capital ou estar em recuperação judicial. Para a coleta destes dados foram utilizados os formulários de referência das empresas listadas na B3 e foram selecionados 5 anos de resultados, culminando em um $n$ de 1.190 observações/ano. As empresas foram alocadas de acordo com os segmentos nos quais elas estão classificadas pela B3.

Tabela 1 - Segmentos das empresas da amostra

\begin{tabular}{lccc}
\hline Segmentos & Familiares & Não Familiares & Total \\
\hline Bens Industriais & 15 & 14 & 29 \\
Construção e Transportes & 28 & 22 & 50 \\
Consumo Cíclico & 37 & 20 & 57 \\
Consumo Não Cíclico & 19 & 22 & 41 \\
Materiais Básicos & 25 & 13 & 38
\end{tabular}


Petróleo e Gás

Tecnologia da Informação

Telecomunicações

Total

Fonte: dados da pesquisa

$\begin{array}{ccc}1 & 5 & 6 \\ 3 & 5 & 8 \\ 4 & 5 & 9 \\ 132 & 106 & 238\end{array}$

As empresas familiares compõem a maior parte da amostra (cerca de 55\%). É possível identificar que essa característica está relacionada ao que discutem Aldrighi e Mazzer Neto (2007) sobre o fato de que as empresas no Brasil, em muitos casos, possuem uma estrutura de propriedade em que há concentrações superiores a 50\%. Diante disso, como o mercado de capitais brasileiro ainda é pouco desenvolvido (Aldrighi \& Mazzer Neto, 2007), muitas empresas ligadas aos setores menos desenvolvidos tecnologicamente (maior grau de tangibilidade, maiores valores de ativos, maiores patrimônios etc.) são as corporações mais presentes listadas em bolsa.

\subsection{Métodos e testes de robustez}

A pesquisa possui uma metodologia quantitativa baseada em uma relação causal entre índices de investimento e estrutura de propriedade e controle familiar (bem como variáveis de interação) das empresas brasileiras. 0 modelo consiste no uso de regressões lineares múltiplas, que, segundo Wooldridge (2010), funcionam para testar o impacto de várias variáveis sobre uma variável dependente em uma relação simultânea. A pesquisa apresenta uma equação básica a ser utilizada para a resolução das hipóteses propostas.

Invest $/ A T_{i t}=\alpha_{i t}+\beta_{F A M}(\text { Familiar })_{i t}+\beta_{\text {Control }}(\text { Variáveis de controle })_{i t}+\varepsilon_{i t}$

Em que:

Invest $/ A T_{i t}=$ índice de investimentos em CapEx sobre ativo total.

Familiar = Empresa Familiar (0 ou 1)

Control = Variáveis de controle (tamanho, tangibilidade, fluxo de caixa, endividamento e marketto-book).

Tal equação também apresenta algumas variações, como a inclusão de variáveis de interação para a Equação 2 que buscam responder as hipóteses $H_{1}, H_{2}$ e $H_{3}$.

Como testes de robustez, o primeiro teste utilizado consistiu em um modelo de dados em painel com efeitos aleatórios. Wooldridge (2010) demonstra que uma regressão utilizando dados em painel com efeitos aleatórios exibe características importantes por ser mais robusta que o método de mínimos quadrados ordinários agrupado (POLS) e por poder identificar o peso de variáveis constantes (ou com pouca diferença ao longo do tempo), tais como as características de propriedade e de controle familiar das empresas da amostra. Este teste serve como complementar para as hipóteses $H_{1}, H_{2}$ e $H_{3}$.

O segundo teste de robustez refere-se a uma separação amostral baseada em Chrisman e Patel (2012), os quais afirmam que empresas familiares em condições financeiras diferentes tendem a agir de maneira diferente. Sendo assim, utilizou-se de uma segmentação baseada no $\mathrm{L}_{n}$ das receitas totais. Esse teste visa responder as hipóteses $H_{4}$ e $H_{5}$.

\section{Análise de Resultados}

\subsection{Estatísticas descritivas}

Os dados descritivos referentes à amostra da pesquisa refletem a grande variação entre as características das empresas. Mesmo diante de um perfil de empresas de capital aberto no Brasil e levando em consideração que a maior parte delas estão em setores mais focados em manufatura industrial (Aldrighi \& Mazzer Neto, 2007), as empresas apresentaram variabilidade entre si. A Tabela 2 apresenta as estatísticas sumárias das empresas da amostra. Já a Tabela 3 apresenta as diferenças das médias entre empresas familiares e não familiares.

Tabela 2 - Estatísticas sumárias das empresas da amostra

\begin{tabular}{lccccc}
\hline Variáveis & Média & Mediana & Desvio-Padrão & Mínimo & Máximo \\
\hline Total de ativos (R\$ milhões) & 8.679 & 1.265 & 43.341 & 0,34 & 752.966 \\
Lucro líquido (R\$ milhões) & 3.468 & 258,8 & 25.678 & -174.346 & 3.878 .137 \\
Valor de mercado (R\$ milhões) & 7.168 & 954,8 & 30.683 & 1,00 & 380.247 \\
Market-to-book & 0,79 & 0,78 & 0,76 & 0,001 & 16,1 \\
\hline
\end{tabular}




\begin{tabular}{lccccc}
\hline Índice de pagamento de dividendos (\%) & 2,15 & 0,7 & 5,10 & 0,0 & 65,7 \\
Índice de investimento em CapEx (\%) & 6,22 & 39,2 & 8,30 & 0,0 & 98,2 \\
Índice de endividamento (\%) & 25,8 & 25,4 & 19,0 & 0,0 & 93,9 \\
Fluxo de caixa & 0,33 & 0,27 & 0,29 & $-0,02$ & 0,99 \\
Capital Imobilizado & 0,29 & 0,26 & 0,23 & 0,0 & 0,90 \\
\hline
\end{tabular}

Como itens relevantes da Tabela 3, pode-se citar o tamanho dos ativos, o que corrobora os resultados encontrados por Anderson e Reeb (2003), em que o tamanho de empresas familiares é menor. Outros itens relevantes consistem no valor de mercado e market-to-book, que podem representar a forma como a empresa é vista pelo mercado. Diferentemente de Anderson e Reeb (2003), as empresas familiares da amostra possuem menor precificação pelo mercado e menores oportunidades de crescimento (embora não significantes estatisticamente).

Tabela 3 - Comparação entre empresas familiares e não familiares

\begin{tabular}{lccc}
\hline Variáveis & Familiares & Não Familiares & Teste T \\
\hline Número de observações & 635 & 489 & - \\
Total de ativos (R milhões) & 4.780 & 13.932 & $3,51^{*}$ \\
Lucro líquido (R\$ milhões) & 966 & 6.846 & $3,80^{*}$ \\
Índice de investimento em bens de capital & 0,049 & 0,079 & $6,17^{*}$ \\
Índice de endividamento & 0,28 & 0,25 & $2,91^{*}$ \\
Market-to-book (oportunidades de crescimento) & 0,70 & 0,83 & $2,21^{*}$ \\
Valor de mercado (R\$ milhões) & 2.517 & 13.020 & $5,40^{*}$ \\
Fluxo de caixa & 0,35 & 0,31 & $1,97^{*}$ \\
Taxa de dividendos & 0,016 & 0,028 & $3,50^{*}$ \\
Retorno sobre investimento & 0,04 & $-0,16$ & 1,15 \\
Imobilização do capital (tangibilidade) & 0,295 & 0,290 & 0,339 \\
\hline
\end{tabular}

*95\% de confiança

Isso pode ser analisado juntamente com a taxa de pagamento de dividendos, em que as empresas familiares pagam uma quantia menor do que as não familiares (estatisticamente significante). Por fim, a variável de interesse, investimento em bens de capital, apresentou valores bem menores (estatisticamente significantes) para as empresas familiares, o que contrapõe os valores apresentados por Anderson et al. (2012).

\subsection{Discussão dos resultados}

Buscando compreender os efeitos específicos da estrutura de propriedade e controle familiar e da interação dessa variável com características estruturais específicas das firmas, a Tabela 4 apresenta os resultados do modelo OLS para as três equações analisadas e os modelos com efeitos aleatórios para a equação 3.

Tabela 4 - Impacto da estrutura de propriedade e controle familiar nos investimentos em bens de capital (modelo OLS e Efeitos Aleatórios com a variável empresa familiar e variáveis de interação)

\begin{tabular}{lcccc} 
& \multicolumn{2}{c}{ Variável Dependente: Índice de investimentos em bens de capital (Capex/TotaldeAtivos) } \\
\cline { 2 - 5 } Variáveis & Modelo 1 & Modelo 2 & Modelo 3 & Modelo 3 (efeitos aleatórios) \\
\hline Intercepto & 0,0187 & $-0,0047$ & $0,0526^{*}$ & 0,0727 \\
Familiar & $-0,0182^{* * *}$ & - & $-0,1166^{* * *}$ & $-0,1334^{* *}$ \\
Familiar * Market-to-book & - & 0,0087 & 0,0091 & 0,0103 \\
Familiar * Tamanho & - & $-0,0043^{* * *}$ & 0,0021 & 0,0034 \\
Familiar* Tangibilidade & - & $-0,0960^{* *}$ & $-0,0923^{* * *}$ & $-0,1125^{* * *}$ \\
Familiar * Fluxo de Caixa & - & $-0,0014$ & $-0,0017$ & 0,0059 \\
Familiar * Idade & - & $0,0255^{* * *}$ & $0,0318^{* * *}$ & $0,0334^{* * *}$ \\
Familiar * Endividamento & - & $-0,0425^{*}$ & $-0,0436^{*}$ & $-0,066^{*}$ \\
Receitas & $-0,0043^{*}$ & $-0,0029$ & $-0,0027$ & $-0,0030$ \\
Tamanho & $0,0089^{* * *}$ & $0,0110^{* * *}$ & $0,0072^{* * *}$ & 0,0072 \\
Tangibilidade & $0,1048^{* * *}$ & $0,1658^{* * *}$ & $0,1644^{* * *}$ & $0,1721^{* * *}$ \\
Fluxo de Caixa & $-0,0063^{*}$ & $-0,0068$ & $-0,0070$ & $-0,0098^{*}$ \\
Market-to-book (defasado) & 0,0039 & $-0,00120$ & $-0,0023$ & $-0,0032$ \\
Índice de endividamento & 0,0195 & $0,0441^{* *}$ & $0,0406^{*}$ & 0,0549 \\
Idade & $-0,0121^{* * *}$ & $-0,0269^{* * *}$ & $-0,0291^{* * *}$ & $-0,0304^{* * *}$ \\
Dummies para segmento & Sim & Sim & Sim & Sim \\
Dummies para ano & Sim & Sim & Sim & Sim \\
no Observações & 863 & 863 & 863 & 863 \\
$\mathrm{R}^{2}$ ajustado & 0,2063 & 0,2545 & 0,2612 & 0,2583 \\
\hline
\end{tabular}


***99\% de confiança; **95\% de confiança; *90\% de confiança

Os resultados encontrados pelos modelos são consistentes com a literatura sobre investimentos em empresas familiares. Além disso, estão em linha com as hipóteses propostas.

No tocante à hipótese $H_{1}$, os resultados foram satisfatórios. Nas equações 1 e 3 pelo modelo OLS e pelo modelo com efeitos aleatórios, eles apresentaram betas significantes. Para a equação 1 , a variável de interesse (Familiar) exibiu um $\beta=-0,018(p<0,01)$. Já para a equação 3 , mostrou um peso ainda maior do que a equação 1 . Os resultados apresentaram um $\beta=-0,11(p<0,01)$. No modelo com a equação 3 utilizando efeitos aleatórios, exibem um $\beta=-0,13(p<0,05)$. Esses resultados são dissonantes dos encontrados por Anderson e Reeb (2003), cujos dados apontam que os gastos em bens de capital das empresas familiares são superiores aos gastos das não familiares. Contudo, tomando como base as literaturas sobre riqueza socioemocional e autopreservação (Miller et al., 2011; Chua et al., 2015) e sobre o comportamento de empresas familiares em condições de risco e incerteza (Blanco-Mazagatos et al., 2007), torna-se possível afirmar que, diante de um contexto de crise, as empresas baseadas em uma estrutura familiar decidem realizar investimentos mais seguros enquanto aguardam um ambiente menos assimétrico.

Como o Brasil passou a ter problemas de crédito, alta da inflação e incertezas econômicas a partir de 2011 e como as medidas governamentais de liberação de crédito não funcionaram como o esperado, o ambiente econômico nacional teve uma grande deterioração em comparação ao período de boom das commodities de 2004-2008 (Inoue, Lazzarini \& Musachio, 2013; Gonçalves, 2015). Portanto, a hipótese $H_{1}$ apresenta tanto sustentação teórica quanto empírica nas evidências encontradas para as empresas brasileiras, dados os problemas de crédito encontrados no país.

No que concerne à hipótese $H_{2}$ e às equações 2 e 3 (modelo OLS e efeitos aleatórios), a interação da variável relativa à propriedade e controle familiar com variáveis estruturais específicas das firmas (tamanho, tangibilidade, fluxo de caixa, endividamento e market-to-book) mostrou resultados significantes para três variáveis de interesse. As variáveis significantes foram a interação entre controle familiar e tamanho $(\beta=-0,004 ; p<0,01)$, controle familiar e tangibilidade $(\beta=-0,09 ; p<0,05)$ e controle familiar e endividamento $(\beta=-0,04(p<0,10)$. Estes resultados exibem magnitudes diferentes daqueles em que as variáveis tamanho e tangibilidade, sem interação com a variável controle familiar, apresentam resultados positivos e significantes, sendo que a variável tamanho apresenta um $\beta=0,01(p<0,01)$ e a variável tangibilidade expressa um $\beta=0,16(p<0,01)$.

Portanto, fica a questão: por que os resultados para empresas familiares são negativos? Correlacionando o tamanho das empresas e a restrição financeira, afirma-se que as empresas familiares podem agir de maneira mais conservadora mesmo com a possibilidade de minimizar a restrição de crédito por suas características (Campello et al., 2010). Outra fundamentação teórica que respalda a afirmação de que a propriedade familiar gera impactos negativos para a política de investimentos das empresas familiares consiste no conceito de autopreservação (Miller et al., 2011).

Ainda para a hipótese $H_{2}$, os resultados da interação da variável controle familiar e índice de endividamento mostraram um $\beta=-0,04(p<0,10)$ e diagnosticaram que quanto maior o índice de endividamento, menos as empresas familiares passaram a investir em comparação com as não familiares. De acordo com consulta exploratória a dados oficiais, as taxas de juros no período pré-crise de 2008 estavam em 12,5\% a.a. e tiveram uma queda estipulada pelo Banco Central em 2009 de 8,65\% a.a. Essas taxas voltaram a subir em 2011 para $12 \%$ a.a. e, em 2012, o governo novamente adotou uma política fiscal expansionista de crédito, mas os efeitos não foram tão positivos. Além disso, deve-se dizer que o cenário de crédito no Brasil acaba por ser bastante complicado e com taxas de juros elevadas. Assim, o conservadorismo financeiro e a busca pela perenidade das empresas familiares (Gomez-Mejia et al., 2013; Chua et al., 2015), aliados ao contexto de assimetria e de pouca estabilidade nas taxas de juros, funcionam como causadores de impactos negativos ainda maiores para as empresas familiares.

A última hipótese a ser apresentada antes do teste de robustez consiste na hipótese $H_{3}$. Para a amostra completa, os resultados indicam que a idade é um fator negativo para o investimento das empresas. Desta forma, os investimentos caem conforme as empresas envelhecem (os coeficientes apresentaram significância estatística para todos os modelos OLS e para o modelo com efeitos fixos). Em contraponto a este resultado e em consonância com os dados apresentados por Sharma e Salvato (2011), Anderson et al. (2012) e Chrisman e Patel (2012), a perenidade (por meio da proxy idade) é um fator relevante para que as empresas familiares realizem investimentos maiores do que as não 
familiares.

0 próximo item a ser analisado consiste no teste de robustez, apresentado pela Tabela 5, em que as empresas são separadas em dois grupos. 0 primeiro consiste nas empresas que obtiveram receitas inferiores e o segundo consiste naquelas que apresentaram receitas superiores à mediana das receitas das empresas da amostra.

Tabela 5 - Impactos da estrutura de propriedade utilizando segmentações de receita anual

Variável Dependente: Índice de investimentos em bens de capital (Capex/TotaldeAtivos)

\begin{tabular}{lcc}
\hline Variáveis & Receitas $<$ Mediana & Receitas $>$ Mediana \\
\hline Intercepto & $-0,1708$ & 0,0383 \\
Familiar & $0,2410^{* *}$ & $-0,1229^{* *}$ \\
Familiar * Market-to-book & 0,0215 & $-0,0056$ \\
Familiar * Tamanho & $-0,0257^{* * *}$ & 0,004 \\
Familiar * Tangibilidade & $-0,1064^{* *}$ & $-0,082^{* *}$ \\
Familiar * Fluxo de Caixa & 0,0026 & $-0,0189$ \\
Familiar * Idade & $0,0284^{* * *}$ & $0,0238^{* * *}$ \\
Familiar * Endividamento & $-0,0025^{* * *}$ & $-0,0125$ \\
Receitas & $0,0062^{* * *}$ & $-0,0123^{* *}$ \\
Tamanho & $0,0242^{* * *}$ & $0,0143^{* * *}$ \\
Tangibilidade & $0,1467^{* * *}$ & $0,1281^{* * *}$ \\
Fluxo de Caixa & $-0,0026$ & $0,0318^{* * *}$ \\
Market-to-book (defasado) & $-0,0147^{*}$ & 0,0011 \\
Índice de endividamento & $0,0025^{* * *}$ & 0,0026 \\
Idade & $-0,0268^{* * *}$ & $-0,0162^{* * *}$ \\
Dummies para segmento & Sim & Sim \\
Dummies para ano & Sim & Sim \\
no Observações & 393 & 485 \\
$\mathrm{R}^{2}$ ajustado & 0,3312 & 0,3093 \\
\hline
\end{tabular}

***99\% de confiança; **95\% de confiança; *90\% de confiança.

Estes resultados funcionam como um teste de robustez que responde às hipóteses $H_{4} H_{5}$. A hipótese $H_{4}$ visa confirmar as proposições da riqueza socioemocional apresentadas por Miller et al. (2011), Chrisman e Patel (2012), Gomez-Mejia et al. (2012) e Chua et al. (2015) no tocante à estrutura de propriedade e ao comportamento visando à perenidade. Para esses autores, as empresas podem agir de duas formas visando um aumento da riqueza socioemocional: com base no comportamento de autopreservação e no comportamento de maximização da riqueza para a família.

Para o modelo que explorou a parte da amostra com receitas abaixo da mediana das empresas, as variáveis de propriedade e controle familiar $(\beta=0,24 ; p<0,05)$, bem como a variável de interação entre empresa familiar e idade $(\beta=0,02 ; p<0,00)$, apresentaram resultados positivos e significantes. Entretanto, no modelo que utilizou a parte da amostra com receitas acima da mediana das empresas, a variável propriedade e controle familiar $(\beta=-0,12 ; p<0,05)$ exibiu resultado negativo. Já a variável de interação entre estrutura e idade $(\beta=0,02 ; p<0,00)$ apresentou resultado positivo e significante. A Figura 1 demonstra, em uma relação quadrática, o comportamento das decisões de investimento para uma empresa familiar a partir das variações da receita, além de mostrar que quando a receita ainda está longe de um ponto-alvo, as empresas familiares realizam investimentos mais robustos e só voltam a realizar investimentos similares (ou até maiores) quando suas receitas são muito superiores. 


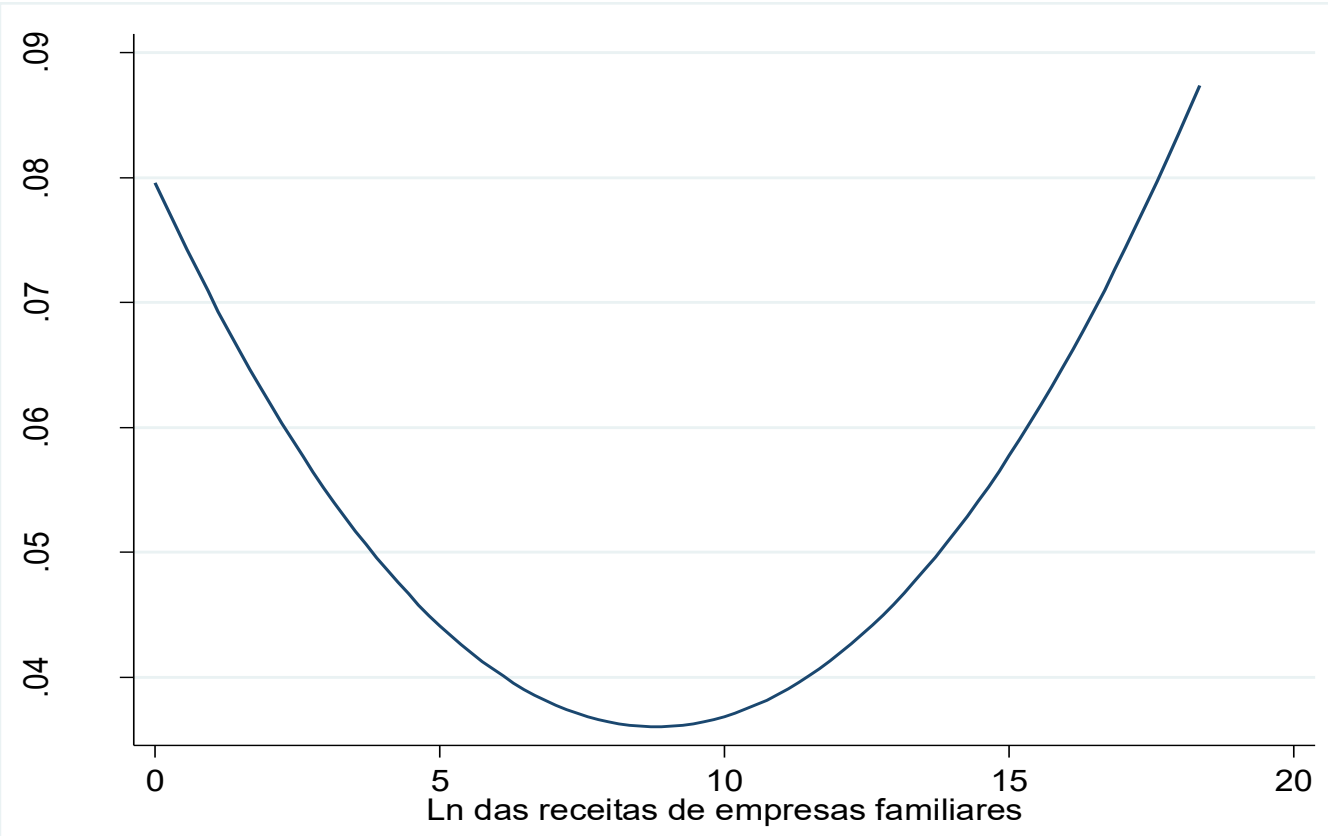

Figura 1 - Relação entre índice de investimentos e receitas de empresas familiares.

A hipótese $H_{5}$ também analisa o impacto das variáveis de interação entre estrutura de propriedade e controle familiar com características específicas da firma. A hipótese está baseada no pressuposto de que empresas que estão próximas ou que passaram de pontos-alvo podem reduzir seus investimentos por acreditarem estar em uma situação ideal (Ouellette \& Wood, 1998; Chrisman \& Patel, 2012; Patel \& Cooper, 2013). Ao analisar um modelo com empresas de uma amostra com receitas abaixo da mediana, as variáveis de interação entre estrutura de propriedade e tamanho $(\beta=-0,02 ; p<0,00)$ e de interação entre estrutura de propriedade e tangibilidade $(\beta=-0,10 ; p<0,00)$ apresentaram resultados negativos e significantes. A explicação é que, conforme as empresas aumentam sua quantidade de ativos e tangibilidade, a necessidade de grandes investimentos em bens de capital se torna menor. Já para as empresas com receitas acima da mediana, a variável de interação com a tangibilidade $(\beta=-0,08 ; p<0,00)$ manteve a tendência de impactos negativos, o que reforça os pressupostos teóricos.

Como corolário, vale ressaltar que, no modelo com a amostra de empresas que obtiveram receitas abaixo da mediana, a variável de interação entre propriedade e controle familiar e índice de endividamento $(\beta=-0,002 ; p<0,00)$ apresentou um valor negativo e estatisticamente significante. Isso corrobora a hipótese $H_{5}$ em relação ao impacto de características específicas da firma aliadas ao controle familiar, mas também corrobora o ideal de autopreservação mencionado por Miller et al. (2010), Patel e Cooper (2013) e Chua et al. (2015).

\subsection{Implicações teóricas e práticas}

0 estudo apresenta um modelo estatístico alinhado tanto em sua formulação quanto em seus resultados com alguns dos principais estudos da área de finanças corporativas para empresas familiares (Anderson et al., 2012; Chrisman \& Patel; 2012). Desta forma, os resultados ilustram como os comportamentos de aversão ao risco e de autopreservação das empresas familiares ocorreram no Brasil mesmo em um período de relativa estabilidade econômica e institucional. Outros aspectos importantes consistem na segmentação de empresas segundo seu faturamento, o que está alinhado com a proposição de risco de empresas familiares proposta por Anderson e Reeb (2003) e Miller et al. (2011), segundo a qual as empresas familiares podem ter um comportamento voltado para a autopreservação, entretanto, quando estão distantes de um ponto focal, agem de maneira mais agressiva para melhorar a sua situação futura. Isso ocorre, sobretudo, pela busca da perpetuidade da organização sob o controle do grupo familiar (Chrisman \& Patel, 2012). Ademais, entende-se que a riqueza da família e os resultados da empresa estão, muitas vezes, entrelaçados e, diante disso, a busca pela maximização do valor dos sócios extrapola os conceitos delineados nas discussões iniciais sobre conflito de agência (Villalonga \& Amit, 2006). 
Como implicações práticas decorrentes desta pesquisa, torna-se importante demonstrar as considerações mais relevantes: a) impacto da estrutura de propriedade e controle familiar nos índices de investimento - resultados estatisticamente significantes do impacto da variável familiar sobre o índice de investimento; b) entendimento sobre como o ambiente institucional brasileiro, mesmo com relativa estabilidade, condiciona uma situação de maior aversão ao risco em grupos familiares - segundo Almeida e Campello (2007), o tamanho, a tangibilidade e o custo de capital influenciam na captação de recurso de terceiros, sobretudo em países com mercado de capitais pouco desenvolvido; c) compreensão sobre como os aspectos de autopreservação e de conservadorismo dos investimentos das empresas familiares influenciaram os níveis de investimento - seguindo os pressupostos estabelecidos por Anderson e Reeb (2012) e Chrisman e Patel (2012), as empresas familiares baseiam suas decisões na preservação da riqueza da família e na orientação de longo prazo e, portanto, podem tomar decisões menos arriscadas devido ao contexto institucional costumeiramente frágil para investimentos mais arriscados. Desta forma, as evidências encontradas podem auxiliar pesquisadores, tomadores de decisão e consultores envolvidos com as temáticas de investimento e empresas familiares, pois apresentam conceitos que ainda estão à margem da discussão teórica sobre o campo de empresas familiares no Brasil (Borges et al., 2012). Deve-se dizer que o entendimento dos conceitos de aversão ao risco e de autopreservação dos grupos familiares pode ser uma ferramenta importante para melhorar o processo decisório das empresas familiares, auxiliar nas decisões de investimento em condições de aumento de risco e de mudanças de acionistas controladores ou de gestores familiares.

\section{Considerações Finais}

Os resultados apresentados pela pesquisa confirmaram as hipóteses e as pressuposições teóricas. As hipóteses afirmavam que os investimentos das empresas familiares brasileiras seriam menores do que os das não familiares. Nos modelos com a equação completa (tanto por OLS quanto com efeitos aleatórios), os resultados expuseram que as empresas familiares investiram em torno de 11\% a 13,5\% menos do que as não familiares no período entre 2009 e 2013.

A interação da variável família com variáveis específicas da empresa também corroborou as hipóteses propostas. A chamada dualidade (mixed gamble) apresentada por vários autores também se encontra nesta pesquisa. Isso fica claro pela geração de impactos negativos a partir da interação da variável família com outras variáveis importantes como tamanho e tangibilidade. Assim sendo, as empresas, quando passam de um dado objetivo (que pode ser uma comparação com outras empresas), tendem a reduzir seus investimentos, pois focam apenas em manter a riqueza para a família. Enquanto isso, como a perenidade também é um foco das empresas familiares, quanto maior a idade de uma empresa familiar maiores serão os seus investimentos em bens de capital. Devido a esses resultados, a dualidade da riqueza socioemocional também fica evidenciada neste trabalho.

Em finanças corporativas, os investimentos em bens de capital são considerados lumpy (gastos elevados) e, portanto, os condicionantes macroeconômicos (problemas de liquidez e altas taxas de juros) e as características das empresas brasileiras foram importantes para o estudo. Contudo, para responder as duas últimas hipóteses da pesquisa, tornou-se necessário separar a amostra em duas partes: uma delas para empresas com receita acima da mediana e a outra para empresas com receita abaixo da mediana. Após essa segmentação, os resultados foram diferentes dos encontrados nos modelos normais. Isso ocorreu devido ao fato de que as empresas familiares abaixo da mediana investiram aproximadamente $24 \%$ mais do que as não familiares. Já as empresas familiares com receita superior à mediana investiram aproximadamente $12 \%$ menos do que as não familiares.

Por fim, deve-se ressaltar que as limitações da pesquisa consistem no uso exclusivo de empresas de capital aberto listadas em bolsa, não compreendendo todo o universo das empresas brasileiras (cuja maioria é de capital fechado). Como contribuições, encontrou-se que as empresas familiares brasileiras apresentam comportamento diferente das norte-americanas para os gastos elevados com bens de capital e têm maior aderência aos comportamentos de autopreservação e de conservadorismo nas decisões de investimento. Como sugestões de uma agenda de pesquisa no Brasil para a temática das empresas familiares, deve-se esperar a realização de análises contemplando outras decisões de investimento (P\&D e capital de giro), além do aumento do período de análise e da inclusão de empresas que não sejam de capital aberto.

\section{Referências}


Agca, S., Mozumdar, A. (2008). The impact of capital market imperfections on investment-cash flow sensitivity. Journal of Banking and Finance, 32, 207-216.

Aldrighi, D. M., Mazzer Neto, R. (2007). Evidências sobre as estruturas de propriedade de capital e de voto das empresas de capital aberto no Brasil. Revista Brasileira de Economia, 61 (2), 129-152.

Almeida, H., Campello, M. (2007). Financial Constraints, Asset Tangibility, and Corporate Investment. Review of Financial Studies, 20 (5), 1429-1460.

Anderson, R. C., Reeb, D. M. (2003). Founding-family ownership and firm performance: evidence from the S\&P 500. The Journal of Finance, 58 (3), 1301-1328.

Anderson, R. C., Duru, A., Reeb, D. M. (2012). Investment policy in family controlled firms. Journal of Banking \& Finance, 36, 1744-1758.

Alves, P. F., Gomes, N. L., Cavalcante, E. J. (2014) Impacto do investimento em máquinas e equipamentos sobre a inovação tecnológica e a produtividade das firmas industriais brasileiras (Texto de Discussão 1930). Brasília: Instituto de Pesquisa Econômica Aplicada - IPEA.

Baysinger, B. D., Kosnik, R. D., Turk, T. A. (1991). Effects of board and ownership structure on corporate R\&D strategy. Academy of Management Journal, 34 (1), 205-214.

Berrone, P., Cruz, C., Gomez-Mejia, L. R. (2012). Socioemotional wealth in family firms: theoretical dimensions, assessment approaches, and agenda for future research. Family Business Review. 25 (3), 258-279.

Borges, A. F., Lescura, C., Oliveira, J. L. (2012). 0 campo de pesquisas sobre empresas familiares no Brasil: análise da produção científica no período 1997-2009. Organizações \& Sociedade, 19(61), 315-332.

Blanco-Mazagatos, V. Quevedo-Puente, E., Castrillo, L. A. (2007). The trade-off between financial resources and agency costs in the family business: an exploratory study. Family Business Review, 20 (3), 199-213.

Brown, J. R, Petersen, B. C. (2009). Why has the investment-cash flow sensitivity declined so sharply? Rising R\&D and equity market developments. Journal of Banking and Finance, 33, 971-984.

Brunaldi, E. O., Kayo, E. K., \& Securato, J. R. (2015). Influence of cash flow on leverage adjustments: empirical evidence from Brazil. Revista de Finanças Aplicadas, 3(1), 1-20.

Campello, M., Graham, J. R., Harvey, C. R. (2010). The real effects of financial constraints: evidence from a financial crisis. Journal of Financial Economics, 97, 470-487.

Chrisman, J. J., Patel, P. C. (2012). Variations in R\&D investments of family and nonfamily firms: behavioral agency and myopic loss aversion perspectives. Academy of Management Journal, 55 (4), 975-997.

Chua, J. H., Chrisman, J. J., De Massis, A. (2015) A closer look at socioemotional wealth: its flows, stocks, and prospects for moving forward. Entrepreneurship Theory and Practice. 39 (2)173-182.

Cleary, S., (1999). The relationship between firm investment and financial status. Journal of Finance, 54, 673-692.

Cleary, S., (2000). The sensitivity of Canadian corporate investment to liquidity. Canadian Journal of Administrative Sciences, 17 (3), 217-232.

Cleary, S.; Povel, P.; Raith, M., (2007). The U-shaped investment curve: Theory and evidence. Journal of Financial and Quantitative Analysis, 42, 1-40

Crespí, R., \& Martín-Oliver, A. (2015). Do family firms have better access to external finance during crises? Corporate Governance (Oxford), 23(3), 249-265.

Dudley, E. (2012). Capital structure and large investment projects. Journal of Corporate Finance, 18 (5), 1168-1192.

Ellul, A. Pagano, M., Panuzi, F. (2010). Inheritance law and investment in family firms. American Economic Review. 100, 2414-2450.

Fama, E. F., Jensen, M. (1983). Separation of Ownership and Control. Journal of Law and Economics. 26 (2), 301-325.

Fazzari, S., Hubbard R. G., Petersen, B. C. (1988). Financing Constraints and Corporate Investment. Brookings Papers on Economic Activity, 1, 141-206.

Gallo, M. A., Tàpies, J., Cappuyns, K. (2004). Comparison of family and nonfamily business: financial logic and personal preferences. 17 (4), 303-318.

Graham, J. R., Harvey, C. R., Puri, M. (2013). Managerial attitudes and corporate actions. Journal of Financial Economics, 109, 103-121.

Gedajlovic, E., Carney, M., Chrisman, J. J., \& Kellermanns, F. W. (2012). The Adolescence of Family Firm Research: Taking Stock and Planning for the Future. Journal of Management, 38(4), 1010-1037. 
Gervais, S., Odean, T. (2001). Learning to be overconfident. The Review of Financial Studies, 14 (1), 127.

Gomez-Mejia, L. R., Campbell, J. T., Martin, G., Hoskisson, R. E., Makri, M., Sirmon, D. G. (2013). Socioemotional wealth as a mixed gamble: revisiting family firm R\&D investments with the behavioral agency model. Entrepreneurship Theory and Practice, 37 (6), 1351-1374.

Gonçalves, C. E. (2015). Too tight and too lose: monetary policy in Brazil in the last decade (Working Paper). Disponível em: http://www.joserobertoafonso.ecn.br/biblioteca-virtual/item/4771-monetarypolicy-in-brazil-gon\%C3\%A7alves.html

Gonçalves, C. E. \& Guimarães, B. (2015). Sovereign default risk and commitment for fiscal adjustment. Journal of International Economics, 95(1), 68-82. Disponível em:

https://doi.org/10.1016/j.jinteco.2014.11.008.

Guariglia, A. (2008). Internal financial constraints, external financial constraints, and investment choice: Evidence from a panel of UK firms. Journal of Banking \& Finance, 32(9), 1795-1809.

IBGE - Instituto Brasileiro de Geografia e Estatística. (2020). Pesquisa de inovação: 2017. Rio de Janeiro: IBGE, 2020. Disponível em: https://biblioteca.ibge.gov.br/index.php/biblioteca-catalogo?view=detalhes\&id=2101706

Inoue, C. F. K. V., Lazzarini, S. G., Musachio, A. (2013). Leviathan as a minority shareholder: firm-level implications of state equity purchases. Academy of Management Journal, 56 (6), 1775-1801.

James, H. 1999, Owner as manager, extended horizons and the family firm. International Journal of the Economics of Business, 6, 41-56.

Jensen, M.; Meckling, W. (1976). Theory of the firm: managerial behavior, agency costs and ownership structure. Journal of Financial Economics, 3 (4), p. 305-360.

Kaplan, S., Zingales, L. (1997). Do financing constraints explain why investment is correlated with cash flow? Quarterly Journal of Economics, 112, 169-215.

Kayo, E. K., Brunaldi, E. O., \& Aldrighi, D M. (2018). Capital Structure Adjustment in Brazilian Family Firms. Revista de Administração Contemporânea, 22(1), 92-114.

Kothari, S.P., Laguerre, T.E., Leone, A. J. (2002). Capitalization versus expensing: Evidence on the uncertainty of future earnings from capital expenditures versus R\&D outlays. Review of Accounting Studies 7, 355-382.

La Porta, R., Lopez-de-Silanes, F., Shleifer, A. (1999). Corporate ownership around the world. Journal of Finance, 54, 471-517.

Malmendier, U., Tate, G. (2005). Does overconfidence affect corporate investment? CEO overconfidence measures revisited. European Financial Management, 11 (5), 649-659.

Massell, B. F. (1962). Investment, innovation, and growth. Econometrica, 30 (2) 239-252.

Miller, D., Le Breton-Miller, I., Lester, R. H., \& Cannella, A. A., Jr.. (2007). Are family firms really superior performers? Journal of Corporate Finance, 13,: 829-858.

Miller, D., Le Breton-Miller, I., \& Lester, R. H. (2010). Family ownership and acquisition behavior in publicly traded companies. Strategic Management Journal, 31, 201-223.

Miller, D., Le Breton-Miller, I., Lester, R. H. (2011). Family and lone founder ownership and strategic behavior: social context, identity and institutional logics. Journal of Management Studies, 48 (1), 1-25.

Modigliani, F., Miller, M. H. (1958). The cost of capital, corporation finance and the theory of investment. American Economic Review, 48 (3) 261-297.

Myers, S. C., Majluf, N. S. (1984). Corporate financing and investment decisions when firms have information that investors do not have. Journal of Financial Economics, 13, 187-221.

Ouellette, J. A., Wood, W. (1998). Habit and intention in everyday life: the multiple processes by which past behavior predicts future behavior. Psychological Bulletin, 124, 54-74.

Patel, P. C., Cooper, D. (2013) Structural power equality between family and non-family TMT members and the performance of family firms. Academy of Management Journal, 57 (6), 1624-1649.

Schulze, W. S., Lubatkin, M. H., Dino, R. N. (2003). Exploring the agency consequences of ownership dispersion among the directors of private family firms. Academy Management Journal, 46 (2), 179-194.

Sharma, P., Salvato, C. (2011). Exploiting and exploring new opportunities over life cycle stages of family firms. Entrepreneurship Theory and Practice, 35, 1199-1205.

Shleifer, A., Vishny, R.W. (1997). A Survey of Corporate Governance. The Journal of Finance, 52 (2). 737 783.

Villalonga, B., Amit, R. (2006). How do family ownership, control and management affect firm value? 
Journal of Financial Economics, 80, 385-417.

Wiseman, R. M, Gomez-Mejia, L. R. (1998). A behavioral agency model of managerial risk taking. Academy of Management Review, 23 (1) 133-153.

Wooldridge, J. M. (2010). Introdução à econometria. São Paulo: Cengage Learning.

Zellweger, T. (2007). Time horizon, costs of equity capital, and generic investment strategies of firms. Family Business Review, 20 (1), 1-15. 